\title{
Molecular Mapping of Resistance to Blight in an Interspecific Cross in the Genus Castanea
}

\author{
T. L. Kubisiak, F. V. Hebard, C. D. Nelson, Jiansu Zhang, R. Bernatzky, H. Huang, S. L. Anagnostakis, and R. L. Doudrick
}

First and eighth authors: USDA Forest Service, Southern Research Station, Southern Institute of Forest Genetics, 23332 Highway 67, Saucier, MS 39574; second author: American Chestnut Foundation Research Farms, 14005 Glenbrook Avenue, Meadowview, VA 24361-9703; third author: International Paper Company, Southlands Experiment Forest, 719 Southlands Road, Bainbridge, GA 31717; fourth and fifth authors: University of Massachusetts, Department of Plant and Soil Sciences, French Hall, Box 32910, Amherst 01003-2910; sixth author: 136 Atwood Research Facility, Kentucky State University, Frankfort 40601; and seventh author: Connecticut Agricultural Experiment Station, Box 1106, New Haven 06504.

Accepted for publication 25 March 1997.

\section{ABSTRACT}

Kubisiak, T. L., Hebard, F. V., Nelson, C. D., Zhang, J., Bernatzky, R., Huang, H., Anagnostakis, S. L., and Doudrick, R. L. 1997. Molecular mapping of resistance to blight in an interspecific cross in the genus Castanea. Phytopathology 87:751-759.

A three-generation American chestnut $\times$ Chinese chestnut pedigree was used to construct a genetic linkage map for chestnut and to investigate the control of resistance to Endothia parasitica (chestnut blight fungus). DNA genotypes for 241 polymorphic markers (eight isozymes, 17 restriction fragment length polymorphisms [RFLPs], and 216 random amplified polymorphic DNAs [RAPDs]) were assayed on an $\mathrm{F}_{2}$ family consisting of 102 individuals. Of these markers, 196 were segregating as expected and, subsequently, used for primary linkage mapping. Two isozymes, 12 RFLPs, and 170 RAPDs were mapped to 12 linkage groups spanning a total genetic distance of 530.1 Kosambi centimorgans. $F_{2}$ plants were evaluated for a response to $E$. parasitica infection by directly inoculating them with two unique fungal isolates and measuring canker expansion over a period of 3.5 months. Results were compared with the marker genotype data, thereby identifying genomic regions significantly associated with a resistance response. Single-marker or nonsimultaneous analyses of variance identified seven genomic regions that appear to have an effect on host response. Multiple-marker or simultaneous models suggest that three of these regions have a significant effect on host response, together explaining as much as $42.2 \%$ of the total variation for canker size. At each of the three putative resistance loci, alleles derived from the Chinese chestnut grandparent were associated with smaller canker size, or higher levels of resistance.
American chestnut (Castanea dentata (Marsh.) Borkh.), once one of the most important timber and nut-producing tree species in eastern North America, now exists primarily as stump sprouts across its entire natural range, the victim of a devastating canker disease. The disease, chestnut blight, is caused by an exotic fungal pathogen first identified as Diaporthe parasitica (36), but now known systematically as Cryphonectria parasitica (5). Recent evidence (10) supports retention (40) of this species in the genus Endothia, so we will refer to it as Endothia parasitica (Murrill) P.J. Anderson \& H.W. Anderson.

Although low levels of resistance to blight in American chestnut have been reported (20), none of these trees produce progeny suitable for outplanting. However, cultivars of Asian chestnut species, Japanese chestnut (Castanea crenata Siebold \& Zucc.) and Chinese chestnut (Castanea mollissima Blume), exhibit high degrees of resistance to the disease $(11,19)$. Neither of the Asian chestnut species grows as large, or is as cold hardy, as the natively adapted American chestnut $(14,39)$, so the use of either species to replace American chestnut as a source of quality hardwood timber is impractical.

Numerous crosses between the Asian and American chestnut have been made in an attempt to combine the blight resistance of the former with the desirable timber qualities of the latter $(12,15)$. A number of first-generation hybrids with vigorous growth have

Corresponding author: T. L. Kubisiak; E-mail address: kubisiak@ datasync.com

Publication no. P-1997-0421-02R

This article is in the public domain and not copyrightable. It may be freely reprinted with customary crediting of the source. The American Phytopathological Society, 1997. been produced, but most proved too susceptible for practical use (3). Comparatively fewer second-generation crosses have been evaluated, and most have been backcrosses to the resistant Asian chestnuts (12). Although these trees were highly blight resistant, their tree form, winter hardiness, and forest competitiveness were less than satisfactory.

Above-average resistance in first-generation hybrids obtained from crossing American with Chinese chestnut has been observed (11). When some first-generation hybrids were backcrossed to Chinese chestnut, the percentage of resistant progeny was encouragingly high (slightly $>75 \%$ ). In light of these findings, it has been suggested that the inheritance of blight resistance might be relatively simple, controlled by as few as two partially dominant genes (11).

Assuming that blight resistance is under oligogenic control, it should be a relatively straightforward task to introgress the genes conferring resistance to $E$. parasitica in Chinese chestnut into American chestnut by a series of backcrosses to American chestnut $(1,6,9)$. Repeated backcrossing of select (i.e., the most resistant) American chestnut $\times$ Chinese chestnut hybrids and their progeny to American chestnut would reconstitute the American chestnut genome and, hence, many of its desirable qualities, with the addition of resistance genes from Chinese chestnut. This strategy has since been adopted by The American Chestnut Foundation, and an aggressive backcross breeding program is currently underway (21).

One means for greatly increasing the efficiency of backcross breeding programs is to use selectable molecular markers $(6,34$, 44). Molecular markers and their corresponding linkage maps are making it possible to identify genomic regions that condition resistance $(13,33,38,47)$. Simultaneous selection for marker alleles that bracket regions conditioning resistance and against all other marker 
alleles unique to the donor parent allows the breeder to approach the genotype of the recurrent parent in fewer generations than predicted by theory $(23,24)$.

In the current study, we used a three-generation $C$. dentata $\times C$. mollissima pedigree to construct a genetic linkage map for chestnut and to investigate the genetic control of resistance to chestnut blight. We present our linkage map, indicate which genomic regions appear to be conditioning resistance, and discuss how these markers will be used to increase the efficiency of the backcross breeding program.

\section{MATERIALS AND METHODS}

Mapping population. $F_{2}$ progeny for which results are presented were derived from a cross between the $C$. dentata $\times C$. mollissima $\mathrm{F}_{1}$ hybrids R4T31 and R4T52, located in the Spring lot of Sleeping Giant Chestnut Plantation in Hamden, CT. These $\mathrm{F}_{1}$ trees are descended from the 'Mahogany' Chinese chestnut tree (PI\#70315), archived at the Connecticut Agricultural Experiment Station (CAES), and from the 'Roxbury East\#1' and 'Roxbury\#1' American chestnut trees (Fig. 1). The 'Mahogany' tree was planted in 1929 and is highly blight resistant (2). The American chestnut trees 'Roxbury East\#1' and 'Roxbury\#1' were originally considered to have low levels of blight resistance (19) and used in breeding work conducted at the CAES. The $F_{2}$ progeny were grown in Meadowview, VA, as described by Hebard (21).

To augment the detection of resistance loci, we employed the method of selective genotyping (32). Progeny with the highest and lowest levels of resistance (i.e., those individuals presumably fixed for alternate alleles at major effect resistance loci) were included in the sample. A total of 102 progeny whose resistance phenotype deviated substantially from the mean were selected from an $\mathrm{F}_{2}$ population consisting of 185 trees. Three individuals were accidentally mislabeled during the DNA extraction process. These three individuals were included in the linkage analyses, but were excluded from the marker-based analyses of the morphological trait and blight resistance data.

Isozyme detection. A total of 20 isozyme systems (acid phosphatase $[\mathrm{ACP}]$, alcohol dehydrogenase $[\mathrm{ADH}]$, aminopeptidase [AMP], aspartate aminotransferase [AAT], catalase [CAT], endopeptidase [ENP], esterase [EST], formate dehydrogenase [FDH], $\beta$ galactosidase [GAL], glucose-6-phosphate dehydrogenase [G6PDH], glutamate dehydrogenase [GDH], isocitrate dehydrogenase [IDH], lactate dehydrogenase $[\mathrm{LDH}]$, malate dehydrogenase [MDH], malic enzyme [ME], menadione reductase [MNR], peroxidase [PER], 6phosphogluconate dehydrogenase [PGD], shikimate dehydrogenase [SKD], and superoxide dismutase [SOD]) were assayed on dormant buds using procedures described previously (26). Segregation was scored on a total of $50 \mathrm{~F}_{2}$ individuals (a subset of the 102 progeny).

cDNA cloning for restriction fragment length polymorphism (RFLP) analysis. Total RNA was isolated from $1 \mathrm{~g}$ of young leaves of an unnamed $C$. dentata (New Salem, MA). Poly(A) RNA was prepared from total RNA utilizing the PolyATract system (Promega Corp., Madison, WI). cDNA was synthesized from $1 \mathrm{mg}$ of poly(A) RNA using a cDNA synthesis

\begin{tabular}{|c|c|c|c|c|}
\hline \multirow{2}{*}{$\begin{array}{l}\text { American Chestnut } \\
\text { 'Roxbury East \#l' }\end{array}$} & \multicolumn{2}{|c|}{ Chinese Chestnut } & \multicolumn{2}{|c|}{ American Chestnut } \\
\hline & $\mathrm{x}$ & 'Mahogany' & $\mathrm{x}$ & 'Roxbury \# l' \\
\hline & 1 & & $\downarrow$ & \\
\hline & R4T31 & $\mathrm{x}$ & R4T52 & \\
\hline & & $\downarrow$ & & \\
\hline & & $\mathrm{F}_{2}$ & & \\
\hline
\end{tabular}

Fig. 1. Castanea dentata $\times$ C. mollissima hybrid chestnut pedigree used for this study. kit (Pharmacia LKB Biotechnology Inc., Piscataway, NJ), ligated into the vector pBluescript $\mathrm{SK}(+)$ (Stratagene Cloning Systems; Stratagene Inc., La Jolla, CA), and then used to transform competent DH5 $\alpha$ cells.

RFLP detection. Southern blot analysis was performed on the Chinese chestnut grandparent 'Mahogany', the $\mathrm{F}_{1}$ hybrids R4T31 and R4T52, and an unnamed American chestnut. DNA was isolated from these trees according to procedures reported previously (8). DNAs were digested with HindIII, EcoRI, and EcoRV.

Digested DNA (approximately $1.0 \mu \mathrm{g} / \mathrm{lane}$ ) was separated on $0.9 \%$ agarose and Southern blots were produced (7). Probes were labeled using the random priming technique (17). Filters were hybridized under moderate stringency conditions at $68^{\circ} \mathrm{C}$ for $16 \mathrm{~h}$ (7). The filters were washed at $68^{\circ} \mathrm{C}$ twice in $2 \times \mathrm{SSC}(1 \times \mathrm{SSC}$ is $0.15 \mathrm{M} \mathrm{NaCl}$ plus $0.015 \mathrm{M}$ sodium citrate) and $0.1 \%$ sodium dodecyl sulfate (SDS) for $10 \mathrm{~min}$, next in $1 \times$ SSC and $0.1 \%$ SDS for $20 \mathrm{~min}$, and finally in $0.5 \times \mathrm{SSC}$ and $0.1 \%$ SDS for $20 \mathrm{~min}$.

DNAs obtained from extracts of R4T31 were not of a sufficient quality for enzyme manipulation and electrophoresis. As a result, only polymorphisms between the Chinese grandparent, the anonymous American chestnut, and the $\mathrm{F}_{1}$ parent R4T52, digested with various enzymes, could be used to monitor the segregation of sequences homologous to cDNA clones. This may have limited our information regarding mappable RFLPs. DNA from all $102 \mathrm{~F}_{2}$ individuals was digested and Southern blots were produced. Hybridizations and washes were carried out under the moderate stringency conditions described above.

DNA extraction and random amplified polymorphic DNA (RAPD) amplification. Total nucleic acids were isolated from chestnut leaves using a modification of the cetyltrimethylammonium bromide (CTAB)-based procedure (45). To ensure the purity of the chestnut DNA obtained, a proteinase $\mathrm{K}(0.5 \mathrm{mg})$ digestion was performed subsequent to the addition of $N$-lauroylsarcosine. An additional chloroform/octanol (24:1) extraction also was performed. The RNA component of these individual extracts was removed by incubation in the presence of RNase A (4).

Oligonucleotide 10-mer primers were obtained from either Operon Technologies (Alameda, CA) or J. E. Carlson (University of British Columbia, Vancouver, B.C., Canada). A total of 288 primers were selected for initial screening work. DNA amplification followed protocols reported previously (37). The only modification consisted of doubling the amount of template DNA to $6.25 \mathrm{ng}$ per reaction.

Primer screening and marker scoring. To identify and characterize the segregation of RAPD markers, 10-mer primers were screened against both $\mathrm{F}_{1}$ parents (R4T31 and R4T52) and six $\mathrm{F}_{2}$ progeny. A subset of primers that maximized the number of polymorphisms was selected, and segregation was scored on an additional 96 progeny. The 96 individuals were divided into four progeny sets (24 individuals in each set). Each progeny set was amplified on a different thermal cycler, and those polymorphisms that could be confidently scored across all four sets were included in our analyses. Segregating RAPD markers were identified by the manufacturer primer code corresponding to the 10-mer primer responsible for their amplification, followed by a subscript four-digit number indicating the fragment size in base pairs. To ascertain the grandparental origin of each RAPD polymorphism, the informative primers identified above were screened against a panel of DNAs consisting of the Chinese chestnut and American chestnut grandparents, as well as the $\mathrm{F}_{1}$ parents.

Segregation analysis. Each polymorphism was tested for goodness-of-fit to its expected Mendelian segregation ratio using chi-square analysis (41). Those loci that appeared to be experiencing segregation distortion $(P<0.01)$ were excluded from primary mapping analyses. The software packages LINKAGE-1 (43) and JoinMap version 1.1 (42) were utilized to produce a comprehensive, integrated genetic linkage map for the Chinese chestnut $\times$ American chestnut hybrid genome. Two-point linkages were ini- 


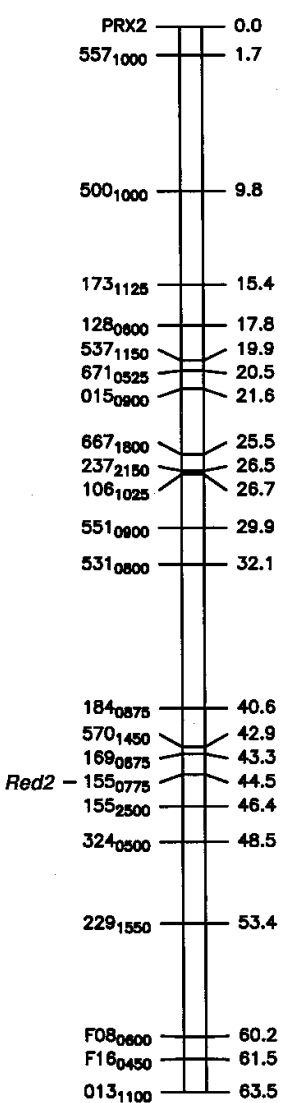

G

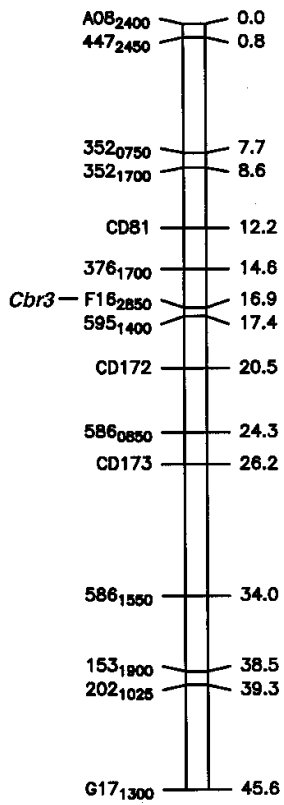

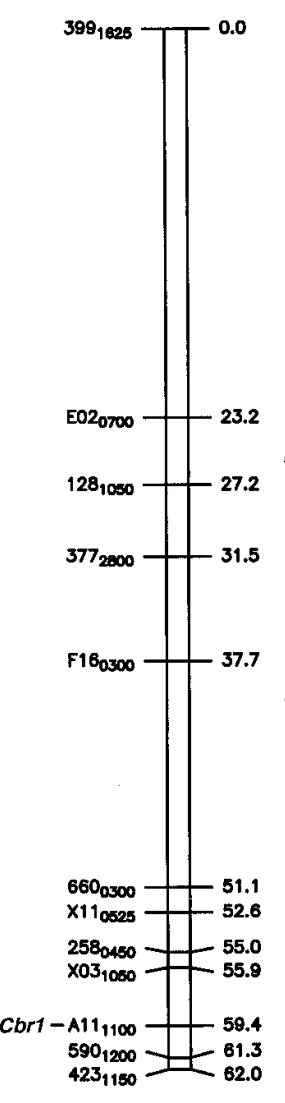

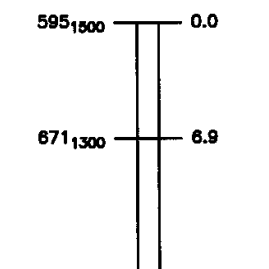

$502_{0625} \underset{16.3}{ }$ ${ }^{108} 8_{1000} \longrightarrow 17.8$ $2090000 \div-18.5$ $306_{0330}+19.6$ A070000 22.0 $237_{0025} \longrightarrow 25.4$ Redi $-146,05050$

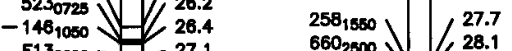

$513_{0600}-27.1$ $532_{1050} \backslash \begin{array}{ll}29.6 & \mathrm{AO7}_{1600}\end{array}=29.4$ 1550050 - 30.1 $5700050-731.2$ $187_{2150}-32.8$ $015.500>=34.7$ $695_{1000} / 34.9$ $229_{1070}-35.2$ $V n h t+595_{1809} / 7 \begin{aligned} & 37.8 \\ & 38.6\end{aligned}$

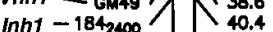
Stp1 - $\mathrm{FOB}_{2500} \longrightarrow \mathbf{}-4.6$ Inh2 - 3060625 -45.2

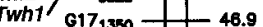

$\left.803_{0350}\right] \begin{aligned} & 32.1 \\ & 33.6\end{aligned}$ 6950675 33.6 ${ }_{262}^{35050} / / \backslash_{34.9}^{34.6}$

$324.100+-39.1$

\begin{tabular}{l|l}
$532_{0425}$ & 40.8
\end{tabular}
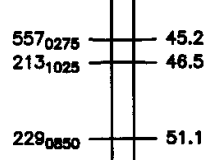

$376_{1050}{ }^{0} 53.1$ stp2-271 $2300+33.7$ $803_{1700}-34.6$ $\left.005_{1025}\right]-37.4$ ${ }_{500_{1000}}>-17.9$

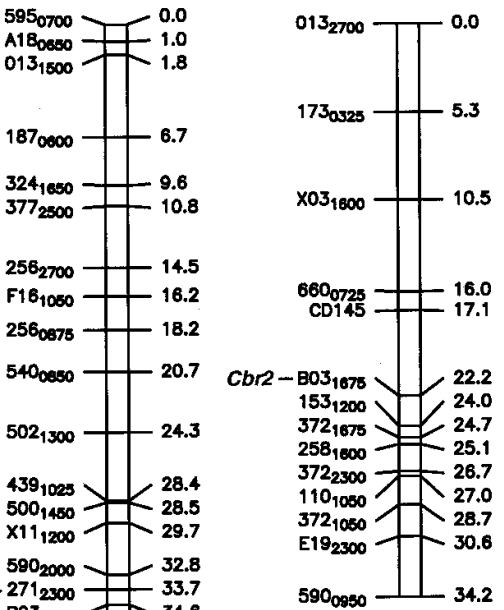

J

$\mathrm{K}$
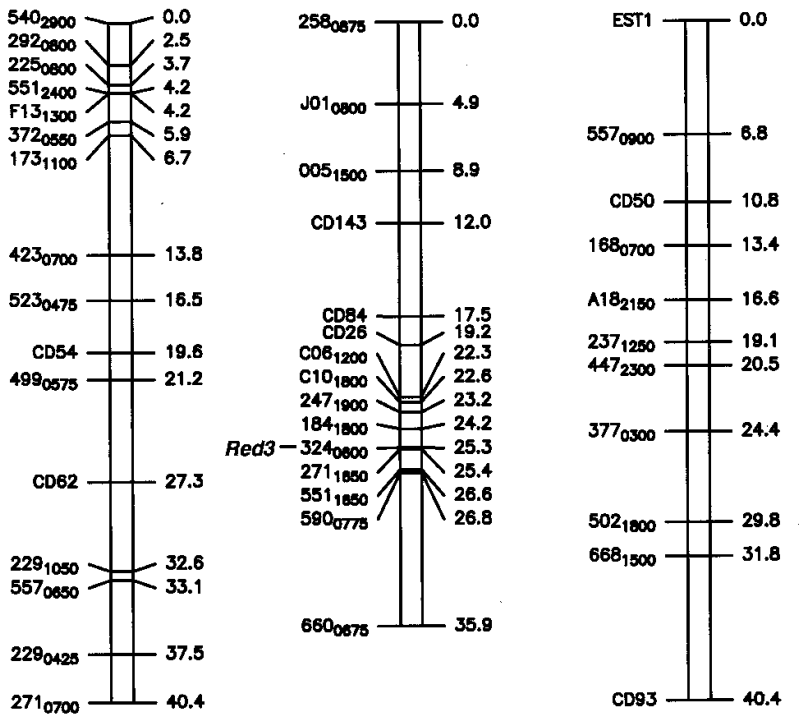
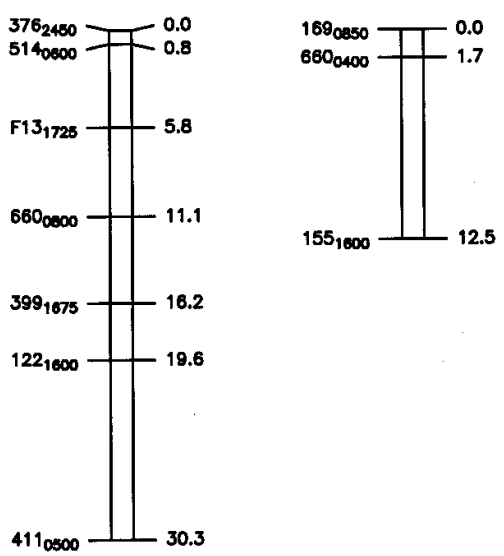

Fig. 2. Recombinational linkage map for chestnut based on inheritance in a Castanea dentata $\times$ C. mollissima $\mathrm{F}_{2}$ population. The 12 linkage groups were arbitrarily assigned a letter designation. Marker identifications are provided on the left side of each group and genetic distance in Kosambi centimorgans (cM) are provided on the right. Random amplified polymorphic DNA markers are identified by the manufacturer primer code corresponding to the 10-mer primer responsible for amplification, followed by a subscript four-digit number indicating the fragment size in base pairs. Those loci beginning with CD or GM are restriction length polymorphism markers. Those loci beginning with three letters are isozyme markers. Abbreviations are as follows: Inh refers to loci determining the presence or absence of interveinal leaf hairs, $V n h$ refers to loci influencing the density of simple vein hairs, Twh refers to loci influencing the density of simple twig hairs, Stp refers to loci influencing stipule size, Red refers to loci influencing stem color, and $\mathrm{Cbr}$ refers to loci conditioning resistance to chestnut blight caused by Endothia parasitica. 
tially examined using both LINKAGE-1 and JoinMap. Linkage groups were established using a log of the odds (LOD) threshold of $\geq 4.0$. For each of the suggested groups, marker orders were determined using JoinMap. In an attempt to map additional regions of the genome, markers with distorted segregation ratios were included in a series of final linkage analyses and tentatively assigned to a linkage group (LOD $\geq 4.0$ ).

Morphological traits. Morphological traits for which $\mathrm{F}_{2}$ progeny were rated include the occurrence of simple hairs on interveinal areas of abaxial leaf surfaces, the density of simple hairs on twigs, the density of simple hairs on abaxial leaf midribs and secondary veins, stipule size, and the degree of green or red stem color. A description of the rating procedures, hypotheses regarding inheritance, and suggested locus nomenclature have been reported previously (22).

Field evaluation of blight resistance. The blight resistance response of the $\mathrm{F}_{2}$ progeny was assessed by using the agar-disk, cork-borer method (20). During the third growing season (1993), each $\mathrm{F}_{2}$ individual was inoculated with two different strains of $E$. parasitica (strains Ep155 and SG2-3). The relative pathogenicity (ability to invade and live on host tissue) of these strains on American chestnut was determined previously (F. V. Hebard, unpublished data). Strain Ep155 was considerably more virulent than strain SG2-3. Two inoculation sites per $F_{2}$ individual were selected approximately 15 to $30 \mathrm{~cm}$ apart. Strain SG2-3 was used to inoculate the acropetal wound site, and strain Ep155 was used to inoculate the basal wound site.

Inoculations were made in late spring (mid-June 1993) using 7to 10-day-old fungal cultures. Plugs of bark $1.5 \mathrm{~mm}$ in diameter, extending to the vascular cambium, were removed from the trees. Similar-sized agar plugs containing the appropriate fungal isolate were inserted directly into the wound, which then was sealed with masking tape to prevent desiccation. Canker evaluations (length, width, stromata production, and canker superficiality and swelling) were made in August and again in September. The mean canker sizes in each month (computed from the length and width) for each isolate were used as relative measures of resistance.

Molecular evaluation of morphological and blight resistance data. The degree of association among the 241 marker loci and the various morphological traits and blight resistance data was investigated by employing single-locus or nonsimultaneous analysis of variance (ANOVA) models, in which the individual markergenotypes were used as class variables (31). The proportion of the phenotypic variance explained by segregation of the marker was determined by the $R^{2}$ value. For the morphological trait data, an

TABLE 1. Distorted markers linked (log of the odds $[\mathrm{LOD}] \geq 4.0$ ) to at least one undistorted marker or at least one other distorted marker

\begin{tabular}{|c|c|c|c|c|c|c|c|c|c|c|c|}
\hline \multirow[b]{2}{*}{ Marker } & \multirow{2}{*}{$\begin{array}{l}\text { Expected } \\
\text { ratio }^{\mathrm{a}}\end{array}$} & \multicolumn{5}{|c|}{ Observed segregation $^{\mathrm{b}}$} & \multirow[b]{2}{*}{$\chi^{2 c}$} & \multirow[b]{2}{*}{$L^{\mathrm{d}}$} & \multirow[b]{2}{*}{$\mathrm{NLM} / \mathrm{NDM}^{\mathrm{e}}$} & \multirow[b]{2}{*}{$\mathrm{LM}^{\mathrm{f}}$} & \multirow[b]{2}{*}{$\mathrm{LOD}^{\mathrm{g}}$} \\
\hline & & $\mathrm{cc}$ & $\mathrm{cc} / \mathrm{ca}$ & $\mathrm{ca}$ & $\mathrm{ca} / \mathrm{aa}$ & aа & & & & & \\
\hline \multicolumn{12}{|c|}{ Linked to at least one undistorted marker } \\
\hline $106_{0800}$ & $3: 1$ & 38 & & & 64 & & $8.17 * * \mathrm{~h}$ & A & 11 & $531_{0800}$ & 10.51 \\
\hline $169_{0300}$ & $1: 1$ & & & 68 & & 33 & $12.13^{* * *}$ & A & 4 & $667_{1800}$ & 14.06 \\
\hline $209_{0325}$ & $1: 1$ & 59 & & 28 & & & $11.04 * * *$ & A & 6 & $155_{0775}$ & 8.62 \\
\hline $209_{1800}$ & $3: 1$ & 39 & & & 62 & & $9.98 * *$ & A & 12 & $155_{2500}$ & 11.96 \\
\hline $483_{2500}$ & $1: 1$ & 74 & & 28 & & & $20.75 * * * *$ & A & 4 & $237_{2150}$ & 10.60 \\
\hline $660_{1300}$ & $3: 1$ & 38 & & & 64 & & $8.17 * *$ & A & 10 & $671_{0525}$ & 14.41 \\
\hline E19 1250 & $1: 1$ & 71 & & 31 & & & $15.69 * * * *$ & A & 7 & $237_{2150}$ & 12.13 \\
\hline F08 2400 & $3: 1$ & 40 & & & 60 & & $12.00^{* * *}$ & A & 13 & $155_{2500}$ & 13.03 \\
\hline $\mathrm{J}_{06} 6_{0525}$ & $3: 1$ & 38 & & & 64 & & $8.17 * *$ & A & 12 & $531_{0800}$ & 12.81 \\
\hline $324_{1675}$ & $1: 1$ & & & 67 & & 23 & $21.51 * * * * *$ & $\mathrm{E}$ & 11 & $540_{0850}$ & 7.53 \\
\hline $209_{2200}$ & $3: 1$ & 11 & & & 88 & & $10.18 * * *$ & G & 2 & CD81 & 5.32 \\
\hline 2920950 & $3: 1$ & & 88 & & & 13 & $7.92 * *$ & $\mathrm{~L}$ & 2 & $660_{0400}$ & 7.07 \\
\hline CD120 & $1: 2: 1$ & 8 & & 42 & & 42 & $36.50^{* * * * *}$ & $\mathrm{~L}$ & 3 & $169_{0850}$ & 6.97 \\
\hline $250_{1025}$ & $1: 1$ & 72 & & 30 & & & $17.29 * * * *$ & M & 1 & $256_{1900}$ & 5.73 \\
\hline \multicolumn{12}{|c|}{ Linked to at least one distorted marker } \\
\hline $292_{1300}$ & $1: 1$ & & & 69 & & 32 & $13.55^{* *}$ & $\mathrm{E}$ & 6 & $\mathrm{~J} 01_{1300}$ & 14.17 \\
\hline $330_{1600}$ & $1: 1$ & 81 & & 16 & & & $43.55^{* * * * *}$ & $\mathrm{E}$ & 3 & $\mathrm{~J} 01_{1300}$ & 19.15 \\
\hline $618_{0725}$ & $1: 1$ & & & 66 & & 35 & $9.51 * *$ & $\mathrm{E}$ & 4 & $292_{1300}$ & 11.01 \\
\hline E09 1675 & $1: 1$ & & & 70 & & 32 & $14.16^{* * *}$ & $\mathrm{E}$ & 6 & $292_{1300}$ & 21.76 \\
\hline $\mathrm{J} 01_{1300}$ & $1: 1$ & & & 81 & & 20 & $36.84 * * * *$ & $\mathrm{E}$ & 5 & $330_{1600}$ & 19.15 \\
\hline $146_{1650}$ & $1: 1$ & 64 & & 29 & & & $13.17 * * * *$ & $\mathrm{~L}$ & 6 & $202_{0700}$ & 13.07 \\
\hline $202_{0700}$ & $1: 1$ & 72 & & 29 & & & 18.31 **** & $\mathrm{L}$ & 6 & $146_{1650}$ & 13.07 \\
\hline $483_{1600}$ & $3: 1$ & 47 & & & 54 & & $24.98 * * * *$ & $\mathrm{~L}$ & 6 & $372_{0450}$ & 8.05 \\
\hline $153_{1400}$ & $1: 1$ & 65 & & 36 & & & $8.33^{* *}$ & M & 4 & $537_{2450}$ & 21.48 \\
\hline $330_{0850}$ & $3: 1$ & 43 & & & 56 & & $17.94 * * * *$ & M & 4 & SKD & 16.68 \\
\hline
\end{tabular}

a Expected Mendelian inheritance ratio.

${ }^{\mathrm{b}}$ Observed number of individuals in each genotypic class. $\mathrm{cc}=$ homozygous for Chinese chestnut alleles; $\mathrm{cc} / \mathrm{ca}=$ ambiguous, one or two Chinese chestnut alleles; $\mathrm{ca}=$ heterozygous; $\mathrm{ca} / \mathrm{aa}=$ ambiguous, one or two American chestnut alleles; and aa $=$ homozygous for American chestnut alleles.

c Observed chi-square for fit to the expected.

${ }^{\mathrm{d}}$ Linkage group to which the marker mapped.

${ }^{\mathrm{e}} \mathrm{NLM}=$ number of undistorted markers linked at LOD $\geq 4.0$ and NDM $=$ number of distorted markers linked at LOD $\geq 4.0$.

${ }^{\mathrm{f}}$ The most tightly linked marker.

$\mathrm{g}$ The largest LOD score suggesting linkage.

h The number of asterisks indicates the probability of lack-of-fit of the observed segregation to the expected. Two asterisks indicate rejection at $P \leq 0.01$, three at $P \leq 0.001$, and four at $P \leq 0.0001$. 
association between a marker and the trait of interest was considered significant if the probability of observing an $F$ value as large as, or larger than, the observed value was $\leq 0.001$. For the blight resistance data, a more liberal threshold $(P \leq 0.01)$ was chosen in an attempt to lower the type II error rate (29).

To reduce the residual inflation common to single-locus models and increase the probability of detecting secondary quantitative trait loci (QTL), multiple-loci or simultaneous models were constructed (46). A separate model was constructed for each linkage group (LG-specific models), allowing for the removal of variation associated with any other QTL that might be present on the same linkage group. The best multivariable ANOVA model was determined by using both the stepwise and maximum $R^{2}$ improvement methods available in the statistical analysis software, SAS (SAS Institute, Cary, NC). For the stepwise technique, the $F$ statistic for a marker to be added to the model had to be significant at the SLENTRY $\leq 0.01$. Once added, any marker that did not produce a significant $F$ at the SLSTAY $\leq 0.01$ was deleted from the model. A set of genome-wide simultaneous (GW) models was then constructed, which included all the significant markers located on different linkage groups. Again, the best multivariable ANOVA model was determined by using both the stepwise and maximum $R^{2}$ improvement methods.

\section{RESULTS}

Current status of the chestnut linkage map. A total of 241 polymorphisms were scored on our $\mathrm{F}_{2}$ population: eight isozymes, 17 RFLPs, and 216 RAPDs. Of the 241 polymorphisms, 45 were found to deviate significantly from their expected Mendelian inheritance ratio based on chi-square analyses $(P \leq 0.01)$. These markers were initially excluded from the linkage analyses. A total of 196 loci were used to construct a primary recombinational linkage map. These 196 loci (six isozymes, 14 RFLPs, and 176 RAPDs) were entered into LINKAGE-1 and JoinMap. Of the 196 loci analyzed, $184(93.9 \%)$ were found to be linked. In total, two isozymes, 12 RFLPs, and 170 RAPDs mapped to 12 linkage groups spanning a total genetic distance of 530.1 Kosambi centimorgans (cM) (Fig. 2). The genetic length of the linkage groups ranged in size from 12.5 to $63.5 \mathrm{cM}$, with an average length of $44.2 \mathrm{cM}$. The genetic distance between markers ranged from 0.0 to $23.2 \mathrm{cM}$, with an average spacing of $2.8 \mathrm{cM}$.

In an attempt to map additional regions of the chestnut genome, linkage analyses were performed that included the entire marker data set (241 markers). Of the 45 markers found to deviate significantly from their expected Mendelian inheritance ratio, 21 were found to be linked to at least one other marker included in the primary linkage analyses (Table 1). An additional 12 distorted markers were found to be linked to at least one other distorted marker (Table 1). A tentative thirteenth linkage group (designated group $\mathrm{M}$ ) was formed among five distorted markers and the previously unlinked primary marker $256_{1900}$ (Table 1). Although an additional 33 markers were added to the map, only an extra $24.1 \mathrm{cM}$ of genetic distance was covered (data not shown).

Molecular markers significantly associated with morphological traits. Interveinal leaf hairs. The abaxial, interveinal leaf surface on sun leaves of American chestnut are glabrous, whereas Chinese chestnut leaves are pubescent. In our population of 102 individuals, 87 were pubescent, 12 were glabrous, and 3 were excluded due to mislabeling during DNA extraction (described in Materials and Methods). Using single-marker ANOVA, 12 markers located on linkage group $\mathrm{C}$ were significantly associated with the presence or absence of interveinal leaf hairs (Table 2). Models specific for linkage group $\mathrm{C}$ suggested that two putative loci determine the presence or absence of interveinal leaf hairs. One locus (Inhl) is most likely located in the vicinity of marker $184_{2400}$, and the other (Inh2) near marker $306_{0825}$ (Fig. 2). A model containing both markers as independent variables had an $R^{2}$ value of 0.526 .
Vein hair density. The petiole, midrib, and secondary veins of Chinese chestnut sun leaves are covered with dense simple hairs, whereas vein hairs are sparse on American chestnut. In our $\mathrm{F}_{2}$ population, most individuals possessed a moderate to high density of vein hairs, and only a few individuals had sparse vein hairs (Table 3). Single-marker ANOVAs performed on vein hair density suggested a significant association for six markers, all of which were located on linkage group C (Table 2). LG-specific models suggested that only a single putative locus, located on linkage group C, significantly influences the density of simple vein hairs. The most likely location of this locus $(V n h l)$ is in the proximity of marker GM49 (Fig. 2).

Twig hair density. Twigs of Chinese chestnut are conspicuously hairy, while hairs are not visible with the naked eye on twigs of American chestnut. Most individuals in our $\mathrm{F}_{2}$ population were conspicuously hairy on their twigs (Table 3). Only two markers (both on linkage group C) were found to be significantly associated with twig hair density based on single-marker ANOVAs (Table 2). LG-specific models suggested that only a single puta-

TABLE 2. Molecular markers significantly associated with the inheritance of various leaf and stem traits in a Castanea dentata $\times$ C. mollissima $\mathrm{F}_{2}$ population based on single-marker analysis of variance models $(P>F \leq 0.001)$

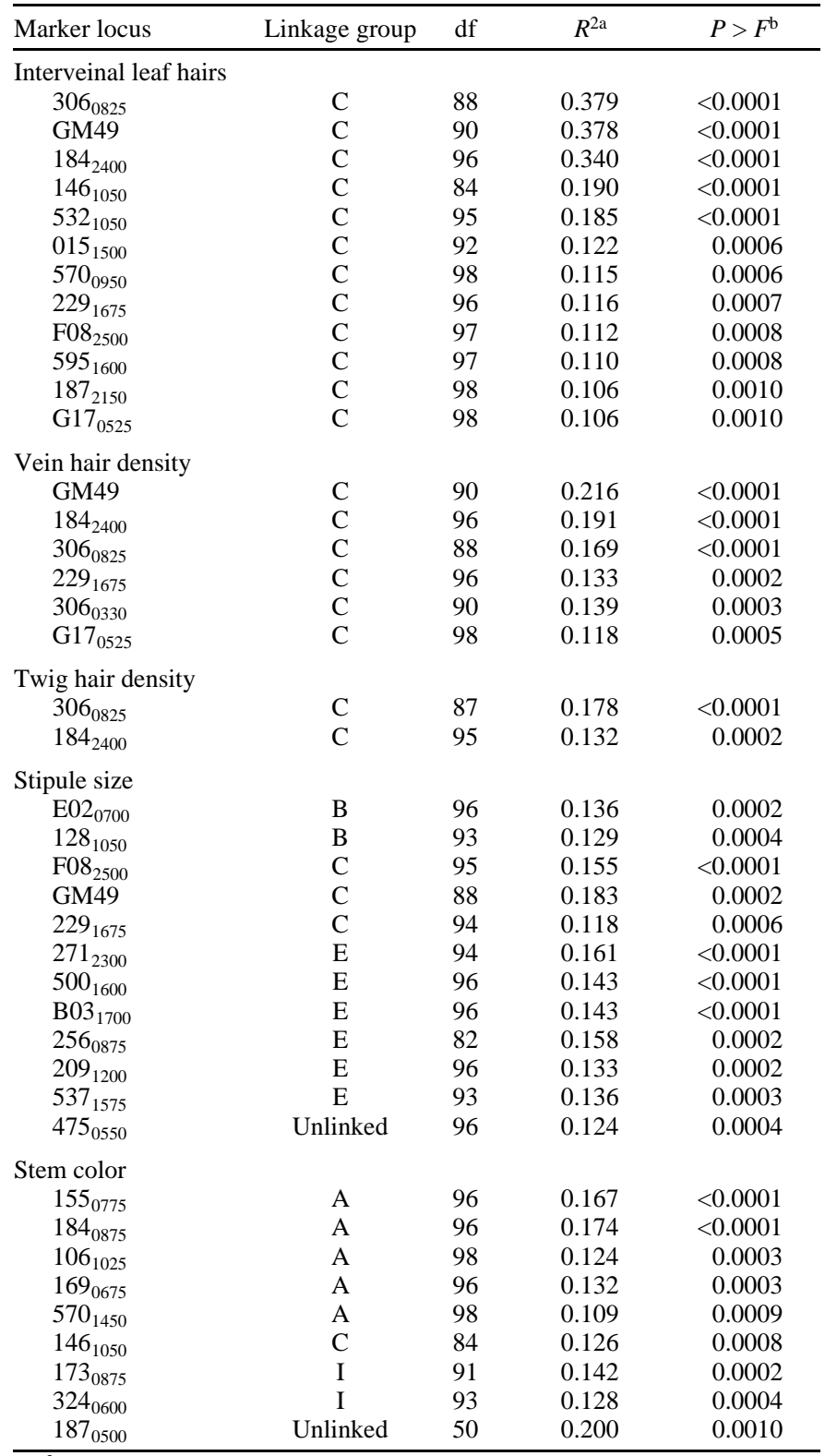

a $R^{2}$ or the proportion of the phenotypic data explained by the marker locus. ${ }^{\text {b }} P>F=$ probability of a greater $F$ value. 
tive locus on linkage group $\mathrm{C}$ significantly influences the density of simple twig hairs. This putative locus (Twhl) is most likely located in the vicinity of marker $306_{0825}$ (Fig. 2).

Stipule size. Stipules of Chinese chestnut are wide at the base (5 to $10 \mathrm{~mm}$ ) and taper to a point, whereas stipules on American chestnut are thinner at the base $(1 \mathrm{~mm})$ and slowly taper to a point. In our $\mathrm{F}_{2}$ population, a fairly normal distribution for stipule size was observed (Table 3 ). A significant association was observed between 12 markers and stipule size (Table 2). LG-specific models suggested the existence of a single locus on each of the groups B, C, and E. GW models suggested the existence of two loci that significantly influence stipule size. These loci (Stpl and Stp2) are most likely located in the vicinity of the markers F08 ${ }_{2500}$ on linkage group $\mathrm{C}$ and $271_{2300}$ on linkage group $\mathrm{E}$, respectively (Fig. 2). A model containing both marker loci had an $R^{2}$ value of 0.285 .

Green or red stem color. Growing American chestnut stems have a reddish color, whereas Chinese chestnut stems are green or tan colored. In our $F_{2}$ population, approximately equal numbers of red- and green-stemmed individuals were observed (Table 3). Nine markers were found to be significantly associated with stem color based on single-marker ANOVAs (Table 2). LG-specific models suggested the existence of only a single putative locus on each of the groups A, C, and I. GW models suggested the existence of three loci that significantly influence stem color. One locus $(\operatorname{Red} 1)$ is most likely located in the proximity of marker $146_{1050}$ on linkage group C, another locus (Red2) in the vicinity of marker $155_{0775}$ on linkage group A, and the third locus (Red3) near marker $324_{0600}$ on linkage group I (Fig. 2). A model including these three loci had an $R^{2}$ value of 0.422 .

Markers significantly associated with resistance to $E$. parasitica. The mean canker size in August for both strains of E. parasitica was chosen as the best single metric of resistance. The September data were excluded from many analyses, because there was a significant interaction between month of measurement and check tree type (American and Chinese chestnut and their first hybrid) in a repeated measures ANOVA. Biologically, the interaction was due to superficial canker expansion between August and September in varieties of Chinese chestnut that did not have extraordinarily high levels of blight resistance. This superficial canker expansion renders less meaningful resistance metrics based solely on canker length and width. A similar interaction between month of measurement and resistance class was seen in the $F_{2}$ progeny when these had been partitioned into resistance classes by discriminant analysis based on check tree canker sizes. Pooling August canker length and width for both strains of E. parasitica was justified, as there were no significant interactions associated

TABLE 3. Frequency distribution of the number of individuals observed in each phenotypic class for various traits in a Castanea dentata $\times$ C. mollissima $\mathrm{F}_{2}$ population $(n=99)$

\begin{tabular}{|c|c|c|c|c|c|c|c|}
\hline \multirow[b]{2}{*}{ Trait } & \multicolumn{7}{|c|}{ Phenotypic class } \\
\hline & High & Medium & Low & None & & & \\
\hline Vein hair density & 61 & 36 & 2 & & & & \\
\hline \multirow[t]{2}{*}{ Twig hair density } & 42 & 51 & 4 & 1 & & & \\
\hline & Large & $\begin{array}{c}\text { Medium } \\
\text {-large }\end{array}$ & $\begin{array}{l}\text { Medium- } \\
\text { small }\end{array}$ & Small & & & \\
\hline \multirow[t]{2}{*}{ Stipule size } & 10 & 44 & 36 & 7 & & & \\
\hline & Green & Red & & & & & \\
\hline \multirow[t]{2}{*}{ Stem color } & 48 & 51 & & & & & \\
\hline & $1 \mathrm{~cm}$ & $2 \mathrm{~cm}$ & $3 \mathrm{~cm}$ & $4 \mathrm{~cm}$ & $5 \mathrm{~cm}$ & $6 \mathrm{~cm}$ & $7 \mathrm{~cm}$ \\
\hline $\begin{array}{l}\text { August mean } \\
\text { canker size }^{\mathrm{a}}\end{array}$ & 1 & 4 & 16 & 24 & 18 & 17 & 18 \\
\hline
\end{tabular}

${ }^{a}$ For purposes of this table, canker sizes were rounded to the nearest whole number. with canker dimension and no significant interaction of fungus strain with either check tree type or $\mathrm{F}_{2}$ resistance class.

The distribution of mean August canker size approximated a normal distribution (Table 3). A total of 34 markers located on seven different linkage groups were found to be significantly associated $(P>F \leq 0.01)$ with a resistance response based on singlemarker ANOVAs (Table 4). LG-specific models suggested the existence of a single locus on each of the groups A, B, C, E, F, G, and $\mathrm{H}$. Results from the GW models support the existence of three putative resistance loci (Table 5). One putative resistance locus $(\mathrm{Cbrl})$ is located on linkage group B and is most likely located near marker A11 1100 (Fig. 2). The band-present alleles at this locus are descended from the American chestnut grandparents; therefore, only two genotypic classes, either Chinese/Chinese (resistant) and American/Chinese or American/American (susceptible) were distinguishable. Individuals possessing two Chinese chestnut alleles at marker $\mathrm{A} 11_{1100}$ had cankers that were an average of 1.44 $\mathrm{cm}$ smaller than individuals carrying at least one American chestnut allele (Table 6). Another putative resistance locus ( $\mathrm{Cbr} 2$ ) is most likely located on linkage group $\mathrm{F}$ in the vicinity of marker B03 1675 (Fig. 2). The band-present alleles at this locus are descended from the American chestnut grandparents. Individuals harboring two Chinese chestnut alleles at marker B $03_{1675}$ had cankers that were an average of $1.26 \mathrm{~cm}$ smaller than individuals carrying at least one American chestnut allele (Table 6). A third putative resistance locus $(\mathrm{Cbr} 3)$ is most likely located on linkage group $\mathrm{G}$ in the proximity of marker $\mathrm{F} 16_{2850}$ (Fig. 2). The band-present alleles at this locus are derived from the American chestnut grandparents. Indi-

TABLE 4. Molecular markers significantly associated with resistance to Endothia parasitica (as measured by mean canker size 2 months after inoculation) in a Castanea dentata $\times C$. mollissima $\mathrm{F}_{2}$ population based on single-marker analysis of variance $(P>F \leq 0.01)$

\begin{tabular}{|c|c|c|c|c|}
\hline Marker locus & Linkage group & $\mathrm{df}$ & $R^{2 \mathrm{a}}$ & $P>F^{\mathrm{b}}$ \\
\hline $557_{1000}$ & A & 95 & 0.068 & 0.0025 \\
\hline $667_{1800}$ & A & 92 & 0.072 & 0.0092 \\
\hline $106_{1025}$ & A & 97 & 0.068 & 0.0094 \\
\hline $\mathrm{A} 11_{1100}$ & B & 97 & 0.228 & 0.0001 \\
\hline $\mathrm{X} 03_{1050}$ & B & 97 & 0.101 & 0.0014 \\
\hline $258_{0450}$ & B & 95 & 0.099 & 0.0018 \\
\hline $423_{1150}$ & B & 96 & 0.087 & 0.0034 \\
\hline $590_{1200}$ & B & 95 & 0.088 & 0.0034 \\
\hline $\mathrm{X} 11_{0525}$ & B & 95 & 0.081 & 0.0048 \\
\hline $106_{1500}$ & $\mathrm{C}$ & 97 & 0.081 & 0.0046 \\
\hline $005_{1025}$ & $\mathrm{E}$ & 96 & 0.103 & 0.0014 \\
\hline $324_{1650}$ & $\mathrm{E}$ & 93 & 0.082 & 0.0052 \\
\hline $500_{1450}$ & $\mathrm{E}$ & 96 & 0.079 & 0.0053 \\
\hline $\mathrm{F} 16_{1050}$ & $\mathrm{E}$ & 95 & 0.079 & 0.0056 \\
\hline B03 1700 & $\mathrm{E}$ & 97 & 0.077 & 0.0057 \\
\hline $540_{0850}$ & $\mathrm{E}$ & 97 & 0.077 & 0.0058 \\
\hline $377_{2500}$ & $\mathrm{E}$ & 92 & 0.076 & 0.0069 \\
\hline $\mathrm{X} 11_{1200}$ & $\mathrm{E}$ & 95 & 0.071 & 0.0089 \\
\hline B03 1675 & $\mathrm{~F}$ & 97 & 0.143 & 0.0001 \\
\hline $372_{2300}$ & $\mathrm{~F}$ & 93 & 0.128 & 0.0004 \\
\hline $258_{1600}$ & $\mathrm{~F}$ & 97 & 0.102 & 0.0013 \\
\hline $110_{1050}$ & $\mathrm{~F}$ & 95 & 0.099 & 0.0018 \\
\hline E19 2300 & $\mathrm{~F}$ & 97 & 0.081 & 0.0044 \\
\hline $153_{1200}$ & $\mathrm{~F}$ & 96 & 0.078 & 0.0060 \\
\hline $372_{1675}$ & $\mathrm{~F}$ & 95 & 0.076 & 0.0066 \\
\hline $209_{2200}$ & $\mathrm{G}^{\mathrm{c}}$ & 94 & 0.157 & 0.0001 \\
\hline $\mathrm{F} 16_{2850}$ & G & 97 & 0.137 & 0.0002 \\
\hline $202_{1025}$ & $\mathrm{G}$ & 96 & 0.114 & 0.0007 \\
\hline $595_{1400}$ & G & 96 & 0.100 & 0.0016 \\
\hline CD172 & $\mathrm{G}$ & 83 & 0.147 & 0.0016 \\
\hline $586_{0850}$ & $\mathrm{G}$ & 97 & 0.095 & 0.0020 \\
\hline CD81 & G & 47 & 0.208 & 0.0053 \\
\hline $423_{0700}$ & $\mathrm{H}$ & 97 & 0.097 & 0.0018 \\
\hline CD175 & Unlinked & 47 & 0.231 & 0.0027 \\
\hline
\end{tabular}


viduals harboring two Chinese chestnut alleles at marker F16 2850 had cankers that were an average of $1.17 \mathrm{~cm}$ smaller than individuals carrying at least one American chestnut allele (Table 6). A model including these three marker loci explained as much as $42.2 \%$ of the variation associated with canker expansion. Up to $48 \%$ of the variation was explained by codominant composite markers constructed for regions encompassing the three markers (data not shown). This latter figure is $73 \%$ of the total genetic variance. The total genetic variance was computed by subtracting the variance for the parental checks from the phenotypic variation of the $\mathrm{F}_{2}$ progeny. The three markers were also the only significant markers in a multivariate ANOVA including the four mean canker sizes for both strains on both measurement dates. There were no significant interactions between markers in the ANOVA using August mean canker size. For these three marker loci, the mean and standard deviation of canker size at each of the eight possible genotypic classes are displayed in Table 6. Individuals possessing more than three resistance-associated alleles had cankers that were an average of $1.99 \mathrm{~cm}$ smaller than individuals harboring three or less resistance-associated alleles.

\section{DISCUSSION}

Chestnut linkage map. In the current study, we utilized a three-generation $C$. dentata $\times C$. mollissima pedigree to construct a genetic linkage map for chestnut and to investigate the control of resistance to E. parasitica. Primary linkage analyses, including only those markers that were segregating at their expected Mendelian inheritance ratio, mapped 184 loci to 12 linkage groups covering a total genetic distance of 530.1 Kosambi cM. Chestnut species are known to contain 12 homologous pairs of chromosomes (30). Although the results of our analyses suggested the existence of 12 linkage groups, we cannot be sure that each group represents a unique chestnut chromosome. In spite of the rather small average spacing between markers $(2.8 \mathrm{cM})$, it appears as if our map is not yet complete, as 12 markers remain unlinked. Using our partial genetic linkage data, we estimated that our primary map currently covers at least $75 \%$ of the chestnut genome (data not shown) (28).

TABLE 5. Molecular markers significantly associated with resistance to Endothia parasitica (as measured by mean canker size 2 months after inoculation) in a Castanea dentata $\times C$. mollissima $\mathrm{F}_{2}$ population based on multiple-marker analysis of variance models $(P>F \leq 0.01)$

\begin{tabular}{|c|c|c|c|c|c|}
\hline Source & df & $\mathrm{SS}^{\mathrm{a}}$ & $\begin{array}{c}\text { Mean } \\
\text { squares }\end{array}$ & $\begin{array}{c}F \\
\text { statistic }\end{array}$ & $P>F^{\mathrm{b}}$ \\
\hline Model & 3 & 90.034 & 30.011 & 22.84 & 0.0001 \\
\hline Error & 94 & 123.501 & 1.313 & & \\
\hline $\begin{array}{l}\text { Corrected } \\
\text { total }\end{array}$ & 97 & 213.536 & \multicolumn{3}{|c|}{$R^{2 \mathrm{c}}=0.422$} \\
\hline Variable & $\begin{array}{l}\text { Parameter } \\
\text { estimate }\end{array}$ & $\begin{array}{c}\text { Standard } \\
\text { error }\end{array}$ & $\begin{array}{c}\text { Type II } \\
\text { SS }\end{array}$ & $F$ & $P>F$ \\
\hline Intercept & -0.551 & 0.674 & 0.878 & 0.67 & 0.4157 \\
\hline $\mathrm{A} 11_{1100}$ & 1.184 & 0.241 & 31.731 & 24.15 & 0.0001 \\
\hline B03 1675 & 1.074 & 0.264 & 21.684 & 16.50 & 0.0001 \\
\hline $\mathrm{F} 16_{2850}$ & 0.960 & 0.250 & 19.449 & 14.80 & 0.0002 \\
\hline
\end{tabular}

Summary of stepwise procedure for dependent variable

\begin{tabular}{lcccccc}
\cline { 3 - 6 } & $\begin{array}{c}\text { Variable } \\
\text { entered/ } \\
\text { removed }\end{array}$ & $\begin{array}{c}\text { Number } \\
\text { in }\end{array}$ & $\begin{array}{c}\text { Partial } \\
R^{2}\end{array}$ & $\begin{array}{c}\text { Model } \\
R^{2}\end{array}$ & $F$ & $P>F$ \\
\hline 1 & ${\mathrm{~A} 11_{1100}}$ & 1 & 0.2276 & 0.2276 & 28.29 & 0.0001 \\
2 & $\mathrm{~B}_{1675}$ & 2 & 0.1029 & 0.3306 & 14.61 & 0.0002 \\
3 & $\mathrm{~F} 16_{2850}$ & 3 & 0.0911 & 0.4216 & 14.80 & 0.0002 \\
\hline
\end{tabular}

a $\mathrm{SS}=$ sum of squares

${ }^{\text {b }} P>F=$ probability of a greater $F$ value.

${ }^{\mathrm{c}} R^{2}$ or the proportion of the phenotypic data explained by segregation of the marker(s).
Meiosis in interspecific hybrids and derived generations is rarely normal and is expected to be more abnormal in more highly differentiated species combinations. Abnormalities have been shown to include reduced recombination, skewed segregation, incomplete disjunction, and production of chromosomal aberrations. Skewed or distorted segregation appears to be common in interspecific crosses between woody perennials. In two different interspecific crosses, the frequency of loci with skewed segregation ranged from $33 \%$ in an interspecific cross in the genus Citrus (16) to $37 \%$ in an interspecific cross in the genus Prunus (18). The percentage of loci demonstrating aberrant segregation in our interspecific chestnut population (18.6\%) suggested that, while these species are taxonomically distinct at the morphological level, their genomes retain a large amount of structural and functional homology. The localization of loci with aberrant segregation to five different linkage groups (A, E, G, L, and M) suggested that regions of these chromosomes may contain structural differences, genes that affect viability, or both. Although the problems associated with aberrant segregation did not preclude our ability to construct a map for hybrid chestnut, they could make it difficult, or even impossible, to obtain precise estimation of marker-QTL linkages in these genomic regions.

Inheritance of morphological traits. Using molecular marker data, we were able to map loci controlling five different morphological traits (Fig. 2). The marker-based analyses suggested that these traits ascribe to simple Mendelian models. These results are in fairly close accordance with those reported previously (22). Hebard (22) suggested that the presence or absence of interveinal leaf hairs is controlled by a single dominant locus with modifiers. Our marker-based analysis suggested that this trait is controlled by two closely linked loci with alleles in coupling. This might partially explain the rejection of 3:1 inheritance of interveinal leaf hair density in the $F_{2}$ population (22). Hebard's (22) data indicates that vein hair density and twig hair density are controlled by two and three different pairs of dominant genes, respectively. Our marker-based analyses suggested that only single dominant genes control each of these traits. It is possible that other loci affecting vein hair and twig hair densities exist; however, current searches lack the power to confidently detect such loci.

TABLE 6. Mean canker size of individuals from a Castanea dentata $\times C$. mollissima $\mathrm{F}_{2}$ population harboring different numbers of putative alleles for blight resistance based on molecular marker genotypes

\begin{tabular}{lccccc}
\hline Marker genotype & PNRA & & & \\
\cline { 1 - 2 } Single markers & & & & & \\
$\quad$ AA or Aa & $0-1$ & & 59 & 5.388 & 1.425 \\
aa & 2 & & 39 & 3.949 & 1.113 \\
Bb or BB & $0-1$ & & 72 & 5.151 & 1.366 \\
bb & 2 & & 26 & 3.887 & 1.421 \\
CC or Cc & $0-1$ & & 66 & 5.195 & 1.271 \\
cc & 2 & & 32 & 4.031 & 1.598 \\
Three markers combined & & & & & \\
aa, bb, cc & 6 & 6 & 7 & 2.601 & 0.515 \\
aa, bb, CC or Cc & $4-5$ & 4.5 & 6 & 3.590 & 0.618 \\
aa, BB or Bb, cc & $4-5$ & 4.5 & 9 & 3.842 & 0.768 \\
AA or Aa, bb, cc & $4-5$ & 4.5 & 2 & 2.725 & 1.945 \\
aa, BB or Bb, CC or Cc & $2-4$ & 3 & 17 & 4.687 & 1.000 \\
AA or Aa, bb, CC or Cc & $2-4$ & 3 & 11 & 5.077 & 1.131 \\
AA or Aa, BB or Bb, cc & $2-4$ & 3 & 14 & 5.053 & 1.674 \\
AA or Aa, BB or Bb, CC or Cc & $0-3$ & 1.5 & 32 & 5.807 & 1.169 \\
\hline
\end{tabular}

${ }^{\mathrm{a}} \mathrm{a}=$ resistance-associated allele at marker $\mathrm{A} 11_{1100} . \mathrm{b}=$ resistance-associated allele at marker $\mathrm{B} 03_{1675} . \mathrm{c}=$ resistance-associated allele at marker $\mathrm{F} 16_{2850}$. $\mathrm{A}, \mathrm{B}$, and $\mathrm{C}=$ susceptiblity-associated alleles.

b PNRA = potential number of resistance alleles.

${ }^{c}$ MNRA $=$ mean number of resistance alleles.

${ }^{\mathrm{d}} N=$ number of individuals with particular marker genotype.

e $\mathrm{MCS}=$ mean canker size (in centimeters) of individuals with particular marker genotype.

f $\mathrm{SD}=$ standard deviation of mean canker size. 
Linkage analyses performed on the various morphological trait data suggested linkage among loci influencing the three trichomerelated traits and stem color, as well as between loci influencing stipule size and stem color (22). Molecular marker-based analyses confirmed the linkage among loci influencing the trichome-related traits and stem color (Fig. 2); however, we could not determine the precise location of these loci in these analyses. In addition, we were not able to determine whether separate loci control each of the trichome-related traits or whether pleiotropy exists. The results of the marker-based analyses help explain the low correlation noted among the various morphological traits and blight resistance (Fig. 2 and Table 7). In general, multigenic inheritance severely reduces the usefulness of these morphological traits as markers for mapping, and their close linkage to each other reduces their utility as selectable markers in our backcrossing program.

Inheritance of blight resistance. Using single-marker or nonsimultaneous ANOVA models, we identified seven genomic regions that appear to condition a resistance response in the host. Multiple-marker models suggested that only three of these genomic regions simultaneously have a significant effect on disease response. That there are only three loci with an intermediate to large effect involved in resistance to E. parasitica in chestnut is in accordance with previous studies (11). Although we found three markers significantly associated with chestnut blight resistance, any combinations of only two of the three markers identified between eight and 12 trees that had a composite mean canker size smaller than those on two of the three types of Chinese chestnut check trees used in this experiment (the August mean canker size for the three sets of Chinese chestnut check trees were 3.8, 3.3, and $1.7 \mathrm{~cm}$; the sizes for the three combinations of markers can be computed from Table 6). Thus, while it is clear that we found no single genomic region that alone could confer blight resistance, from a practical breeding perspective, two regions are sufficient to confer high levels of blight resistance. Even though the multiple-marker models suggested that only three of the seven genomic regions simultaneously have a significant effect on host response, all seven regions are currently being given equal attention in our mapping program until they have been further characterized. The consequences of overlooking a "true" resistance locus far outweigh the time and labor associated with retaining a false-positive or spurious locus.

E. parasitica is endemic to all major chestnut-growing areas of China, and considerable variation in blight resistance has been reported (25). Molecular studies in other chestnut pedigrees may help determine whether genes for resistance from different sources (such as other individuals of Chinese chestnut or other species of chestnut) map to the same or different locations in the genome. Such information would help us identify additional sources of blight resistance and avoid the use of redundant sources of resistance in the breeding program; this would lead to greater efficiency. Intermixed plantings of backcross progeny from different sources of resistance would encourage crossing in the plantings; this might lessen the potential for breakdown of resistance.

Although it was not critical to order all loci precisely for the ANOVA-based analyses performed in this paper, it will eventually become critical to determine the correct gene order in regions flanking putative disease resistance loci. Such information will be

TABLE 7. Correlation among various morphological traits and blight resistance data in a Castanea dentata $\times$ C. mollissima $\mathrm{F}_{2}$ population

\begin{tabular}{lcccccr}
\hline Trait & $\begin{array}{c}\text { Leaf } \\
\text { hairs }\end{array}$ & $\begin{array}{c}\text { Vein } \\
\text { hairs }\end{array}$ & $\begin{array}{c}\text { Trait twig } \\
\text { hairs }\end{array}$ & $\begin{array}{c}\text { Stipule } \\
\text { size }\end{array}$ & $\begin{array}{r}\text { Stem } \\
\text { color }\end{array}$ & $\begin{array}{c}\text { Canker } \\
\text { size }\end{array}$ \\
\hline Leaf hairs & 1.00 & 0.48 & 0.38 & 0.29 & -0.35 & 0.01 \\
Vein hairs & & 1.00 & 0.34 & 0.34 & -0.32 & 0.05 \\
Twig hairs & & & 1.00 & 0.30 & -0.39 & -0.11 \\
Stipule size & & & & 1.00 & -0.37 & -0.16 \\
Stem color & & & & & 1.00 & 0.01 \\
Canker size & & & & & & 1.00 \\
\hline
\end{tabular}

essential in the later backcross generations in which our focus will be to eliminate those regions of the donor genome experiencing selective drag $(24,48)$. Our goal is eventually to saturate the genomic regions harboring putative resistance loci with large numbers of selectable markers. This will be accomplished by performing bulked segregant analysis (35) on the marker genotypes most significantly associated with a resistance response. Once a large number of markers have been identified in each of the regions of interest, analyses will again be carried out to localize the putative resistance loci more precisely. This might best be accomplished in a backcross population or pedigree.

The American Chestnut Foundation is currently backcrossing the resistance from three Chinese chestnut trees ('Nanking', 'Mahogany', and 'FP555') into 15 to 20 lines of American chestnut. The breeding program is focusing primarily on American chestnut trees in the vicinity of Meadowview, VA, but the goal is to restore the American chestnut throughout its entire native range. Thus, to preserve adaptations to local conditions, the hope is to replicate the breeding effort every few hundred miles from Maine to Georgia. Limited information exists regarding the amount and distribution of genetic variation in American chestnut (27). This work has provided information about a large number of mapped markers that can now be used in population genetic studies of chestnut. Such studies currently are being pursued in the hope that results from them will help us better estimate the number of American chestnut parents we need at each location, as well as how many locations are needed across the natural range.

\section{ACKNOWLEDGMENTS}

We thank M. E. Mason and R. C. Schmidtling for critically reviewing this manuscript, and L. S. Nelson and G. N. Johnson for skilled technical assistance.

\section{LITERATURE CITED}

1. Allard, R. W. 1960. Principles of Plant Breeding. John Wiley \& Sons, New York.

2. Anagnostakis, S. L. 1992. Measuring resistance of chestnut trees to chestnut blight. Can. J. For. Res. 22:568-571.

3. Anonymous. 1954. Chestnut blight and resistant chestnuts. U.S. Dep. Agric. Farmers' Bull. 2068.

4. Ausubel, F. M., Brent, R., Kingston, R. E., Moore, D. D., Seidman, J. G., Smith, J. A., and Struhl, K. 1987. Current Protocols in Molecular Biology. John Wiley \& Sons, New York.

5. Barr, M. E. 1979. The Diaporthales in North America with Emphasis on Gnomonia and Its Segregants. Mycologia Memoir 7. J. Cramer, Lehre, Germany.

6. Bernatzky, R., and Mulcahy, D. L. 1992. Marker-aided selection in a backcross breeding program for resistance to chestnut blight in the American chestnut. Can. J. For. Res. 22:1031-1035.

7. Bernatzky, R., and Schilling, A. 1992. Methods for Southern blotting and hybridization. Pages 15-34 in: Plant Genomes: Methods for Genetic and Physical Mapping. T. C. Osborn and J. S. Beckmann, eds. Kluwer Academic Publishers, Dordrecht, the Netherlands.

8. Bernatzky, R., and Tanksley, S. D. 1986. Genetics of actin-related sequences in tomato. Theor. Appl. Genet. 72:314-321.

9. Burnham, C. R. 1981. Blight-resistant American chestnut: There's hope. Plant Dis. 65:459-460.

10. Chen, B., Chen, C.-H., Bowman, B. H., and Nuss, D. L. 1996. Phenotypic changes associated with wild-type and mutant hypovirus RNA transfection of plant pathogenic fungi phylogenetically related to Cryphonectria parasitica. Phytopathology 86:301-310.

11. Clapper, R. B. 1952. Relative blight resistance of some chestnut species and hybrids. J. For. 50:453-455.

12. Clapper, R. B. 1954. Chestnut breeding, techniques and results. J. Hered. 45:107-114.

13. Devey, M. E., Delfino-Mix, A., Kinloch, B. B., and Neale, D. B. 1995. Random amplified polymorphic DNA markers tightly linked to a gene for resistance to white pine blister rust in sugar pine. Proc. Natl. Acad. Sci. U.S.A. 92:2066-2070.

14. Diller, J. D. 1950. The planting and care of blight-resistant chestnuts for forest trees. U.S. Dep. Agric. For. Pathol. Spec. Release 15.

15. Diller, J. D., and Clapper, R. B. 1969. Asiatic and hybrid chestnut trees 
in the eastern United States. J. For. 67:328-331.

16. Durham, R. E., Liou, P. C., Gmitter, F. G., Jr., and Moore, G. A. 1992. Linkage of restriction fragment length polymorphisms and isozymes in Citrus. Theor. Appl. Genet. 84:39-48.

17. Feinberg, A. P., and Vogelstein, B. 1983. A technique for radio-labeling DNA restriction fragments to high specific activity. Anal. Biochem. 132:6-13.

18. Foolad, M. R., Arulsekar, S., Becerra, V., and Bliss, F. A. 1995. A genetic map of Prunus based on an interspecific cross between peach and almond. Theor. Appl. Genet. 91:262-269.

19. Graves, A. H. 1950. Relative blight resistance in species and hybrids of Castanea. Phytopathology 40:1125-1131.

20. Griffin, G. J., Hebard, F. V., Wendt, R. W., and Elkins, J. R. 1983. Survival of American chestnut trees: Evaluation of blight resistance and virulence of Endothia parasitica. Phytopathology 73:1084-1092.

21. Hebard, F. V. 1994. The American Chestnut Foundation breeding plan: Beginning and intermediate steps. J. Am. Chestnut Found. 8:21-28.

22. Hebard, F. V. 1994. Inheritance of juvenile leaf and stem morphological traits in crosses of Chinese and American chestnut. J. Hered. 85:440446.

23. Hillel, J., Schaap, T., Haberfeld, A., Jeffreys, A. J., Plotzky, Y., Cahaner, A., and Lavi, U. 1990. DNA fingerprints applied to gene introgression in breeding programs. Genetics 124:783-789.

24. Hospital, F., Chevalet, C., and Mulsant, P. 1992. Using markers in gene introgression breeding programs. Genetics 132:1199-1210.

25. Huang, H., Carey, W. A., Dane, F., and Norton, J. D. 1996. Evaluation of Chinese chestnut cultivars for resistance to Cryphonectria parasitica. Plant Dis. 80:45-47.

26. Huang, H., Dane, F., and Norton, J. D. 1994. Genetic analysis of 11 polymorphic isozyme loci in chestnut species and characterization of chestnut cultivars by multi-locus allozyme genotypes. J. Am. Soc. Hortic. Sci. 119:840-849.

27. Huang, H., Dane, F., and Norton, J. D. 1994. Allozyme diversity in Chinese, Seguin and American chestnut (Castanea spp.). Theor. Appl. Genet. 88:981-985.

28. Hulbert, T. W., Legg, E. J., Lincoln, S. E., Lander, E. S., and Michelmore, R. W. 1988. Genetic analysis of the fungus, Bremia lactucae, using restriction fragment length polymorphisms. Genetics 120:947-958

29. Jansen, R. C. 1994. Controlling the type I and type II errors in mapping quantitative trait loci. Genetics 138:871-881.

30. Jaynes, R. A. 1962. Chestnut chromosomes. For. Sci. 8:372-377.

31. Keim, P., Diers, B. W., Olson, T. C., and Shoemaker, R. C. 1990. RFLP mapping in soybean: Association between marker loci and variation in quantitative traits. Genetics 126:735-742.

32. Lander, E. S., and Botstein, D. 1989. Mapping Mendelian factors under- lying quantitative traits using RFLP linkage maps. Genetics 121:185-199.

33. Leonards-Schippers, C., Gieffers, W., Schafer-Pregl, R., Ritter, E., Knapp, S. J., Salamini, F., and Gebhardt, C. 1994. Quantitative resistance to Phytophthora infestans in potato: A case study for QTL mapping in allogamous plant species. Genetics 137:67-77.

34. Medina-Filho, H. P. 1980. Linkage of Aps-1, Mi and other markers on chromosome 6. Rep. Tomato Genet. Coop. 30:26-28.

35. Michelmore, R. W., Paran, I., and Kesseli, R. V. 1991. Identification of markers linked to disease-resistance genes by bulked segregant analysis: A rapid method to detect markers in specific genomic regions by using segregating populations. Proc. Natl. Acad. Sci. U.S.A. 88:9828-9832.

36. Murrill, W. A. 1906. A new chestnut disease. Torreya 6:186-189.

37. Nelson, C. D., Kubisiak, T. L., Stine, M., and Nance, W. L. 1994. A genetic linkage map of longleaf pine (Pinus palustris Mill.) based on random amplified polymorphic DNAs. J. Hered. 85:433-439.

38. Newcombe, G., Bradshaw, H. D., Jr., Chastagner, G. A., and Stettler, R. F. 1996. A major gene for resistance to Melampsora medusae f. sp. deltoidae in a hybrid poplar pedigree. Phytopathology 86:87-94.

39. Reed, C. A. 1947. The 1946 status of Chinese chestnut growing in the eastern United States. Natl. Hortic. 26:83-93.

40. Roane, M. K., Griffin, G. J., and Elkins, J. R. 1986. Chestnut blight and other Endothia diseases and the genus Endothia. The American Phytopathological Society, St. Paul, MN.

41. Sokal, R. R., and Rohlf, F. J. 1969. Biometry. W. H. Freeman \& Co., San Francisco.

42. Stam, P. 1993. Construction of integrated genetic linkage maps by means of a new computer package: JoinMap. Plant J. 3:739-744.

43. Suiter, K. A., Wendel, J. F., and Case, J. S. 1983. LINKAGE-1: A PASCAL computer program for the detection and analysis of genetic linkage. J. Hered. 74:203-204.

44. Tanksley, S. D., and Rick, C. M. 1980. Isozymic genetic linkage map of the tomato: Application in genetics and breeding. Theor. Appl. Genet. 57:161-170.

45. Wagner, D. B., Furnier, G. R., Saghai-Maroof, M. A., Williams, S. M., Dancik, B. P., and Allard, R. W. 1987. Chloroplast DNA polymorphisms in lodgepole and jack pines and their hybrids. Proc. Natl. Acad. Sci. U.S.A. $84: 2097-2100$

46. Weisberg, S. 1985. Applied Linear Regression, 2nd ed. John Wiley \& Sons, New York.

47. Young, N. D., Danesh, D., Menancio-Hautea, D., and Kumar, L. 1993. Mapping oligogenic resistance to powdery mildew in mungbean with RFLPs. Theor. Appl. Genet. 87:243-249.

48. Young, N. D., and Tanksley, S. D. 1989. RFLP analysis of the size of chromosomal segments retained around the $\mathrm{Tm}$-2 locus of tomato during backcross breeding. Theor. Appl. Genet. 77:353-359. 